\title{
Further Studies on the Velocity of Diels-Alder Reaction
}

It has generally been accepted that, in the Diels-Alder reaction, a trans-dienophile adds to a diene faster than the corresponding cis-dienophile. ${ }^{1 a-g)}$ On the other hand, our previous finding indicates that the reactivity of maleonitrile is higher than that of fumaronitrile in the addition reaction to 4-carboxymethyl-5-ethoxyoxazole. ${ }^{2)}$

Present report deals with some findings together with considerations on the velocity of the Diels-Alder reaction.

We took three pairs of dienophiles viz cis- and trans-dibenzoylethylenes, dimethyl maleate and dimethyl fumarate, maleonitrile and fumaronitrile as the large, middle and small size dienophiles. The dienes included four oxazole derivatives and tetrachlorofuran.

Table shows that most of trans-dienophiles react faster than the cis-isomer, and that maleonitrile (cis-dienophile) adds faster than fumaronitrile (trans-dienophile) to the dienes. ${ }^{3)}$

TABLE. Reaction Rate Constant at $74^{\circ}$ in Dioxane $\left.\left[10^{6} \cdot k_{2}\left(1 \text { iter mole }{ }^{-1} \mathrm{sec}^{-1}\right)\right]^{a}\right)$

\begin{tabular}{lccccc}
\hline \multicolumn{1}{c}{ Diene } & $\begin{array}{c}\text { 5-Ethoxy- } \\
\text { 4-methyl- } \\
\text { oxazole }\end{array}$ & $\begin{array}{c}\text { 5-Ethoxy- } \\
\text { Dienophile }\end{array}$ & $\begin{array}{c}\text { 4-Benzyl- } \\
\text { oxazole }\end{array}$ & $\begin{array}{c}5 \text {-Ethoxy-4- } \\
\text { methoxy- } \\
\text { oxazole } \\
\text { phenyloxazole }\end{array}$ & $\begin{array}{c}\text { Tetra- } \\
\text { chloro- } \\
\text { furan }\end{array}$ \\
\hline cis-Dibenzoylethylene & 120 & - & - & - & - \\
trans-Dibenzoylethylene & 820 & - & - & - & - \\
Dimethyl maleate & 37.3 & 2.70 & 27.0 & - & - \\
Dimethyl fumarate & 83.3 & 57.0 & 44.7 & - & 13.3 \\
Maleonitrile & 742 & 255 & 172 & 11.3 & 12.0 \\
Fumaronitrile & 700 & 157 & 140 & 13.7 \\
\hline
\end{tabular}

a) The progress of the reaction was followed by the change of the amplitude in the vinyl proton signals of the dienophile using Varian 60 NMR spectrometer.

Sauer and co-workers ${ }^{1 c, d)}$ proposed two factors in order to explain the higher reactivity of trans-dienophiles over cis-dienophiles. First, the steric hindrance in the cis-isomer weakens the activating effect of the substituents on the double bond which comes in contact with diene. Secondly, the compression of the eclipsed $c i s$-substituents increases during the cycloaddition when the $120^{\circ}$ bond angle is reduced to $109^{\circ}$. These two factors, resulting only from the configuration of dienophiles, positively fail to expailn our experimental result, namely, the higher reactivity of maleonitrile over fumaronitrile. Another factor mentioned for discussion by them is the interaction of the $\pi$-electron system between diene and dienophile in the transition complex. Little attention, however, has been paid to this factor. In view of our results, the factor seems to give most reasonable explanation of our results.

1) a) R. Huisgen, H. J. Strum, and H. Wagenhofer, Z. Naturforsch., 17b, 202 (1962); b) J. Sauer, H. Wiest, and A. Mielert, ibid., 17b, 203 (1962); c) J. Sauer, D. Lang, and H. Wiest, ibid., 17b, $206(1962) ; d)$ J. Sauer, D. Lang, and H. Wiest, Chem. Bex., 97, $3208(1964)$; e) J. Sauer, H. Wiest, and A. Mielert, ibid., 97, 3183 (1964); f) J. Sauer, D. Lang, and A. Mielert, Angew. Chem. Intern. Ed. Engl., 1, 268 (1962); g) J. Sauer, ibid., 6, 16 (1967).

2) T. Miki and T. Matsuo, J. Pharm. Soc. Japan, 87, 323 (1967).

3) R. Huisgen, R. Grashey, and J. Sauer described that the reaction rate constant in the addition of fumaronitrile and maleonitrile to cyclopentadiene were 81 and $91 \times 10^{-5} \mathrm{liter} / \mathrm{mole}$ sec at $20^{\circ}$ in dioxane (R. Huisgen, R. Grashey, and J. Sauer in "The Chemistry of Alkenes," S. Patai, Ed., Interscience, New York, 1964, p. 519) and 3280 and $3180 \times 10^{-6} \mathrm{liter} / \mathrm{mole}$ sec at $40^{\circ}$ in dioxane. ${ }^{1 b}$ ) They stated that the difference is lost in the case of the above 1,2-dicyanoethylenes. We have already examined the reaction at $74^{\circ}$ in dioxane and found that the addition of fumaronitrile proceeds much faster than that of maleonitrile. 
It is known that cis-dienophiles form exclusively endo-adducts. This suggests that the interaction of the $\pi$-electrons with the mobilization of two substituents may decrease the activation energy in the transition state. When the dienophiles are small in size like maleonitrile, the difference of the activation energy between cis- and trans-dienophile complexes may be small. When the diene is less reactive and when the substituents of the dienophile are small in size, the decrease of the activation energy by the longer overlapping of $\pi$ electron may be a dominant factor to accelerate the reaction. In our case, less reactivity of dienes resulted into faster addition of maleonitrile over fumaronitrile to these dienes.

We may, therefore, conclude that the interaction of the $\pi$-electron system between diene and dienophile is a significant factor that governs the velocity of the Diels-Alder reaction.

Acknowledgement The authors thank Prof. Y. Yukawa of Osaka University, Dr. S. Tatsuoka and Dr. $\mathrm{Y}$. Abe for kind discussions and support of this work.

\section{Chemical Research Laboratories, Research and Development Division, Takeda Chemical Industries, Ltd. Juso, Osaka}

Received January 18,1971

\author{
TAKUichi Miki \\ Taisuke Matsuo
}

\section{Products from Reaction of Cholesteryl Acetate with Nitrous Acid ${ }^{1)}$}

It is generally known that a double bond reacts with nitrous acid to form an adduct. During our studies on steroids, the double bond in steroids was found to be fairly sensitive to nitrous acid to form interesting products.

Cholesteryl acetate reacted readily with sodium nitrite in acetic acid solution in the presence of conc. sulfuric acid to afford several products. Fractional recrystallization of the products gave I, colorless needles, $\mathrm{mp} 233-236^{\circ}, \mathrm{C}_{29} \mathrm{H}_{48} \mathrm{O}_{4},{ }^{2)}$ in $10 \%$ yield and $\mathrm{II},{ }^{3)}$ colorless needles, $\mathrm{mp} 168.5-170.5^{\circ}, \mathrm{C}_{31} \mathrm{H}_{50} \mathrm{O}_{6} \mathrm{~N}_{2}$, in $c a .50 \%$ yield. The infrared (IR) spectrum $(\mathrm{KBr})$ of I exhibits absorptions at $3410(\mathrm{OH}), 1735(\mathrm{AcO})$, and $1710 \mathrm{~cm}^{-\mathbf{1}}(>\mathrm{C}=\mathrm{O})$, and its nuclear magnetic resonance (NMR) spectrum $\left(100 \mathrm{Mc}, \mathrm{CDCl}_{3}\right.$ ) shows absorptions at $\delta 5.02$ $(1 \mathrm{H}, \mathrm{m})$ and $1.98(3 \mathrm{H}, \mathrm{s})$. These data suggest that I possesses, in its molecule, a hydroxyl

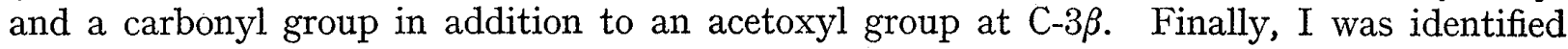
with an authentic sample of $3 \beta$-acetoxy- $5 \alpha$-hydroxycholestan-6-one through mixed melting point, and IR and NMR spectral comparison.

When II was allowed to stand in methanolic potassium hydroxide solution at room temperature, a potassium salt was formed. On treatment with acetic acid, the latter gave an oxime (III), mp 174-175, $\mathrm{C}_{27} \mathrm{H}_{46} \mathrm{O}_{4} \mathrm{~N}_{2}$. Refluxing of III in methanolic potassium hydroxide gave a hydroxy-ketone (IV), $\mathrm{mp} 232-235^{\circ}, \mathrm{C}_{27} \mathrm{H}_{46} \mathrm{O}_{3}$, whose IR spectrum ( $\mathrm{KBr}$ ) exhibited absorptions at $3360(\mathrm{OH})$ and $1705 \mathrm{~cm}^{-1}(>\mathrm{C}=\mathrm{O})$. IV was identified as $3 \beta, 5 \alpha$-dihydroxycholestan-6-one. From these evidences, the presence of AcO- at $\mathrm{C}-3 \beta$, ONO- at $\mathrm{C}-5 \alpha$, and

1) Steroids. $I$.

2) Satisfactory analytical data have been obtained for all compounds reported.

3) During the preparation of this communication, this compound has been presented by Narayanan and others in Tetrahedron Letters, 1970, 4703. 